\title{
IDENTIFICAÇÃO DO CIRCOVÍRUS SUÍNO TIPO 2 E DO PARVOVÍRUS SUÍNO EM FETOS SUÍNOS NATIMORTOS E MUMIFICADOS PROVENIENTES DE GRANJAS NO BRASIL
}

\author{
Danilo Leal Rocha, ${ }^{1}$ Geraldo Camilo Alberton ${ }^{2}$ e José Lúcio dos Santos ${ }^{3}$ \\ 1. Mestre em Ciências Veterinárias pela Universidade Federal do Paraná, Microvet, área de Patologia Suína. \\ E-mail: dleal@terra.com.br \\ 2. Doutor em Ciências Veterinárias, com ênfase em sanidade suína, professor adjunto da Universidade Federal do Paraná \\ 3. Professor adjunto aposentado da Universidade Federal de Viçosa, reponsável técnico do laboratório Microvet.
}

\section{RESUMO}

Investigou-se a presença de sequências genômicas do circovírus suíno tipo 2 (PCV2) e do parvovírus suíno (PPV) em 147 fetos suínos natimortos e mumificados. Estas amostras, provenientes de 39 granjas localizadas em oito estados brasileiros, foram coletadas entre os anos de 2006 e 2008. Utilizaram-se fragmentos de coração e pulmão para extração do DNA total e posterior amplificação de fragmentos correspondentes aos patógenos virais pela técnica de reação em cadeia da polimerase (PCR). Entre as 147 amostras, 74
$(50,3 \%)$ foram positivas ao PCV2 enquanto nove amostras $(6,2 \%)$ apresentaram coinfecção com o PCV2 e o PPV. Nenhuma amostra foi positiva apenas para PPV. Entre as 39 granjas estudadas, 21 $(53,8 \%)$ apresentaram fetos positivos ao PCV2, sendo detectada coinfecção com o PCV2 e o PPV em três (7,7\%). Esses resultados indicam que o PCV2 pode ser um importante agente infeccioso causador de morte embrionária e fetal em suínos no Brasil e deve ser incluído na lista de diagnóstico diferencial.

PALAVRAS-CHAVES: Circovírus suíno tipo 2 (PCV2), falhas reprodutivas, parvovírus suíno (PPV), reação em cadeia da polimerase (PCR), suíno.

\section{IDENTIFICATION OF PORCINE CIRCOVIRUS TYPE 2 AND PORCINE PARVOVIRUS IN PORCINE STILLBIRTHS AND MUMMIFIED FETUSES FROM SWINE FARMS IN BRAZIL}

This study investigated the presence of genome sequences of the porcine circovirus type 2 (PCV2) and porcine parvovirus (PPV) in 147 porcine stillbirths and mummified fetuses. These samples, originated from 39 farms located in eight Brazilian states, were collected between 2006 and 2008. Heart and lung fragments were used for extraction of total DNA and later amplification of correspondent fragments of the virus pathogens through polymerase chain reaction (PCR) technique. Out of 147 samples, 74
(50.3\%) were positive for PCV2 while nine samples (6.2\%) were positive for PCV2 and PPV. None of the samples were positive just for PPV. Out of 39 investigated farms, 21 (53.8\%) had fetuses positive for PCV2 while co-infection with PCV2 and PPV was detected in 3 farms $(7.7 \%)$. These results indicate that PCV2 could be an important infection agent in cases of porcine stillbirths and mummified fetuses in Brazil and must be included at differential diagnostic list.

KEY WORDS: Polymerase chain reaction (PCR), porcine circovirus type 2 (PCV2), porcine parvovirus (PPV), reproductive failure, swine. 


\section{INTRODUÇÃO}

As falhas reprodutivas em suínos, tais como retorno ao cio, aborto, mortes embrionárias e fetais comprometem a meta de produção de leitões nascidos vivos e/ou desmamados de uma granja. Dessa forma, essas falhas reprodutivas podem causar prejuízos econômicos na produção de suínos.

As causas de falhas reprodutivas em suínos podem ser de origem infecciosa ou não infecciosa (HOLLER, 1994). Entre as causas não infecciosas, vários procedimentos de manejo estão sujeitos a influenciar no desempenho reprodutivo do plantel, sendo que as infecciosas podem ser causadas, em especial, por agentes bacterianos e virais (ALMOND, 2006). Dos agentes infecciosos virais mais frequentes detectados em fetos suínos natimortos, mumificados e abortados destacam-se o parvovírus suíno (KIM et al., 2004) e o vírus da síndrome reprodutiva e respiratória dos suínos (MALDONADO et al., 2005). Estudos recentes têm associado o circovírus suíno tipo 2 (PCV2) a falhas reprodutivas com efeitos diretos sobre o embrião ou o feto (WEST et al., 1999; SANCHEZ et al., 2001; JOHNSON et al., 2002; MATEUSEN et al., 2004; PARK et al., 2005; MATEUSEN et al., 2007; HANSEN et al., 2010). No que se refere aos agentes infecciosos citados, é importante destacar que o Brasil é considerado livre do vírus da síndrome reprodutiva e respiratória dos suínos (BRASIL, 2004).

O PCV2, membro da família Circoviridae, é amplamente disseminado na população de suínos (SEGALÉS et al., 2005) e tem sido associado a outras enfermidades, tais como a síndrome da refugagem multissistêmica ou circovirose (ELLIS et al., 1999), a síndrome da dermatite e nefropatia (ROSELL et al., 2000), bem como ao complexo de doenças respiratórias dos suínos (KIM et al., 2003), ao aumento da mortalidade de leitões antes do desmame (BRUNBORG et al., 2007) e à imunossupressão (KAICHUANG et al., 2008).

Em virtude dessa variedade de enfermidades relacionadas ao PCV2, muitos estudos têm sido realizados em todo o mundo. No Brasil, o número de estudos relacionados ao PCV2 é crescente desde o primeiro relato da síndrome da refugagem multissistêmica (CIACCI-ZANELLA, 2003). Entretanto, apenas um estudo relacionado ao PCV2 e a falhas reprodutivas foi encontrado no Brasil, sendo que, no estudo referido, o PCV2 foi considerado como agente infeccioso de pouca importância (PESCADOR et al., 2007). Em outros países, estudos têm relatado aumento nas taxas de aborto, retorno ao cio e fetos natimortos e mumificados relacionados ao PCV2 (WEST et al., 1999; BRUNBORG et al., 2007). ZIZLAVSKY et al. (2008) relataram o PCV2 como o principal agente infeccioso detectado em fetos suínos na República Checa.

O objetivo deste estudo foi investigar, por meio da técnica de PCR, a presença do DNA do circovírus suíno tipo 2 (PCV2) e do parvovírus suíno (PPV) em fetos suínos natimortos e mumificados.

\section{MATERIAL E MÉTODOS}

Para a investigação da presença de fragmentos de DNA do PCV2 e do PPV, utilizaram-se 147 fetos suínos natimortos e mumificados, provenientes de 39 granjas, coletados entre junho de 2006 e junho de 2008. As amostras foram provenientes de granjas localizadas em importantes regiões produtoras de suínos no Brasil: Minas Gerais (14), Paraná (12), Santa Catarina (6), Rio Grande do Sul (2), Goiás (2), Bahia (1), Rio de Janeiro (1) e Espírito Santo (1). Trata-se de granjas que possuíam plantel de 150 a 3.000 matrizes com ciclo de produção completo ou unidades produtoras de leitões, utilizavam vacinação do plantel reprodutivo para o PPV e não utilizavam vacina para o PCV2.

Os fetos foram armazenados em sacos plásticos identificados, congelados a $-20^{\circ} \mathrm{C}$ e posteriormente enviados em caixa isotérmica ao laboratório Microvet, localizado em Viçosa, MG. O período de transporte até o laboratório variou entre 24 e 48 horas. No laboratório, necropsiaram-se os fetos com material estéril para retirada de fragmentos de coração e pulmão.

Procedeu-se à extração do DNA total pelo método padrão fenol-clorofórmio, sugerido por DAVIS et al. (1994) com modificações. Fragmentos de coração e de pulmão de cada feto foram macerados com posterior adição de 3 a $5 \mathrm{~mL}$ de tampão fosfato $\left(\mathrm{Na}_{2} \mathrm{HPO}_{4} 0,04\right.$ $\left.\mathrm{M} ; \mathrm{KH}_{2} \mathrm{PO}_{4} 0,01 \mathrm{M}, \mathrm{pH} 7,4\right)$ para homogeinização. Realizou-se a transferência de $1,5 \mathrm{~mL}$ da suspensão para tubos Eppendorfs, sendo centrifugados a 10.000 $\mathrm{x} g$ por dez minutos. O sobrenadante foi descartado e o sedimento ressuspenso em $1,0 \mathrm{~mL}$ de tampão fosfato com a adição de $125 \mu \mathrm{L}$ de SDS (dodecil sulfato de 
sódio) a 10\%, misturado por inversão e incubado em banho-maria a $65^{\circ} \mathrm{C}$ por trinta minutos. Após esta fase, adicionaram-se $350 \mu \mathrm{L}$ de acetato de potássio $8 \mathrm{M}$, misturado por inversões repetidas e incubado em gelo por sessenta minutos. $\mathrm{O}$ precipitado foi centrifugado a $10.000 \mathrm{x}$ g por quinze minutos a $12^{\circ} \mathrm{C}$. Transferiu-se o sobrenadante para outro tubo Eppendorf, adicionado-se um volume de fenol/clorofórmio (1:1). Após homogeneização por inversões repetidas e separação das fases por centrifugação, por quinze minutos a 10.000 $\mathrm{x} g$, a fase aquosa foi coletada e adicionado um volume de clorofórmio (Merck), misturado por inversões repetidas, sendo as fases separadas por centrifugação por quinze minutos a $10.000 \mathrm{x}$ g. O sobrenadante foi coletado e adicionado de dois volumes de etanol para precipitar DNA total. Centrifugação por dez minutos a $15.000 \mathrm{x}$ g foi realizada para obtenção do sedimento, sendo este lavado com $150 \mu \mathrm{L}$ de etanol $70 \%$. O etanol foi descartado e o sedimento seco em temperatura ambiente por trinta minutos. O sedimento foi ressuspenso em $30 \mu \mathrm{L}$ tampão TE (Tris-HCl 10 mM, pH 7,5, EDTA $1 \mathrm{mM}$ ). Após determinação da concentração por absorbância $260 \mathrm{~nm}$ usando espectofotômetro Ultrospec 1100 pro (Amersham Biosciences), o DNA total foi diluído para uma concentração de $50 \mathrm{ng} / \mu \mathrm{L}$ e estocado a $-80^{\circ} \mathrm{C}$ até o uso. Aplicação de uma alíquota do DNA total em gel de agarose $0,8 \%$ foi realizada para verificar a integridade do DNA total.

Realizou-se a amplificação de fragmentos de DNA específicos de PCV2 e PPV em prova de PCR duplex, seguindo metodologia recomendada por KIM et al. (2003) (Tabela 1). Amplificações foram realizadas em $50 \mu 1$ de mistura de reação contendo 50 ng de DNA total, $20 \mathrm{mM}$ de Tris- $\mathrm{HCl} \mathrm{pH} 8,4,50 \mathrm{mM}$ de $\mathrm{KCl}, 1,25$ $\mathrm{mM}$ de $\mathrm{MgCl}_{2}, 0,2 \mathrm{mM}$ de cada desoxinucleotídeo trifosfatado (dNTP), $1 \mu \mathrm{M}$ de cada oligonucleotídeo e 2,5 U de Taq DNA polimerase (Invitrogen). O programa de amplificação em termociclador Mastercycler gradient (Eppendorf) consistiu de um passo de $94{ }^{\circ} \mathrm{C}$ por 1 minuto, seguido de trinta ciclos de $55^{\circ} \mathrm{C}$ por 1 minuto, $72{ }^{\circ} \mathrm{C}$ por três minutos e finalizada com um passo de extensão de $72{ }^{\circ} \mathrm{C}$ por quatro minutos. Produtos de amplificação foram aplicados em gel de agarose $1,5 \%$ em presença de brometo de etídeo e submetidos a eletroforese a $60 \mathrm{~V}$ e fotografados com luz ultravioleta. Realizaram-se os testes com controle positivo e negativo para validação.

TABELA 1. Oligonucleotídeos utilizados nas amplificações de fragmentos do DNA do circovírus suíno tipo 2 (PCV2) e do parvovírus suíno (PPV) e suas características

\begin{tabular}{|c|c|c|c|c|}
\hline Vírus & Oligonucleotídeos e sequência ( $5^{\prime}$ para 3') & $\begin{array}{l}\text { Posição no } \\
\text { genoma }\end{array}$ & $\begin{array}{c}\text { Tamanho do } \\
\text { produto }\end{array}$ & Referência \\
\hline \multirow{2}{*}{ PCV2 } & D CGGATATTGTAGTCCTGGTCG & $1095-1115$ & \multirow{2}{*}{$481 \mathrm{pb}$} & \multirow{2}{*}{ ELLIS et al., 1999} \\
\hline & R ACTGTCAAGGCTACCACAGTCA & $1570-1549$ & & \\
\hline \multirow{2}{*}{ PPV } & D CCAGCAGCTAACACAAGAAAAGGTTATCAC & $3708-3730$ & \multirow{2}{*}{$226 \mathrm{pb}$} & \multirow{2}{*}{$\begin{array}{l}\text { ARNAULD et al., } \\
1998\end{array}$} \\
\hline & R GTCCATGTTGGTAATCCATTGTAAATC & $3907-3933$ & & \\
\hline
\end{tabular}

$\mathrm{D}$ - direto $\mathrm{R}$ - reverso

\section{RESULTADOS E DISCUSSÃO}

Entre os 147 fetos natimortos e mumificados investigados, foi detectada a presença de pelo menos um agente viral em $83(56,5 \%)$ amostras e $64(43,5 \%)$ amostras foram negativas para os agentes infecciosos investigados. O PCV2 foi detectado em 74 amostras
$(50,3 \%)$ e nove amostras $(6,2 \%)$ apresentaram coinfecção com o PCV2 e o PPV. Nenhuma amostra foi positiva apenas para o PPV. Entre as 39 granjas estudadas, $21(53,8 \%)$ apresentaram fetos positivos ao PCV2, sendo que coinfecção com o PCV2 e o PPV foi detectada em três $(7,7 \%)$ granjas (Tabela 2 ). 
TABELA 2. Presença do circovírus suíno tipo 2 (PCV2) e do parvovírus suíno (PPV) em 147 amostras de fetos suínos natimortos e mumificados provenientes de 39 granjas do Brasil entre junho de 2006 e junho de 2008.

\begin{tabular}{|c|c|c|c|c|c|c|}
\hline \multirow[b]{2}{*}{ Agente viral } & \multicolumn{3}{|c|}{ Amostras } & \multicolumn{3}{|c|}{ Granjas } \\
\hline & Total & Positivas & $\begin{array}{l}\text { Porcentagem de } \\
\text { positivas }\end{array}$ & Total & Positivas & $\begin{array}{l}\text { Porcentagem de } \\
\text { positivas }\end{array}$ \\
\hline PCV2 & 147 & 74 & 50,3 & 39 & 21 & 53,8 \\
\hline PPV & 147 & 0 & 0,0 & 39 & 0 & 0,0 \\
\hline PCV2 e PPV & 147 & 9 & 6,2 & 39 & 3 & 7,7 \\
\hline Pelo menos um agente viral & 147 & 83 & 56,5 & 39 & 24 & 61,5 \\
\hline
\end{tabular}

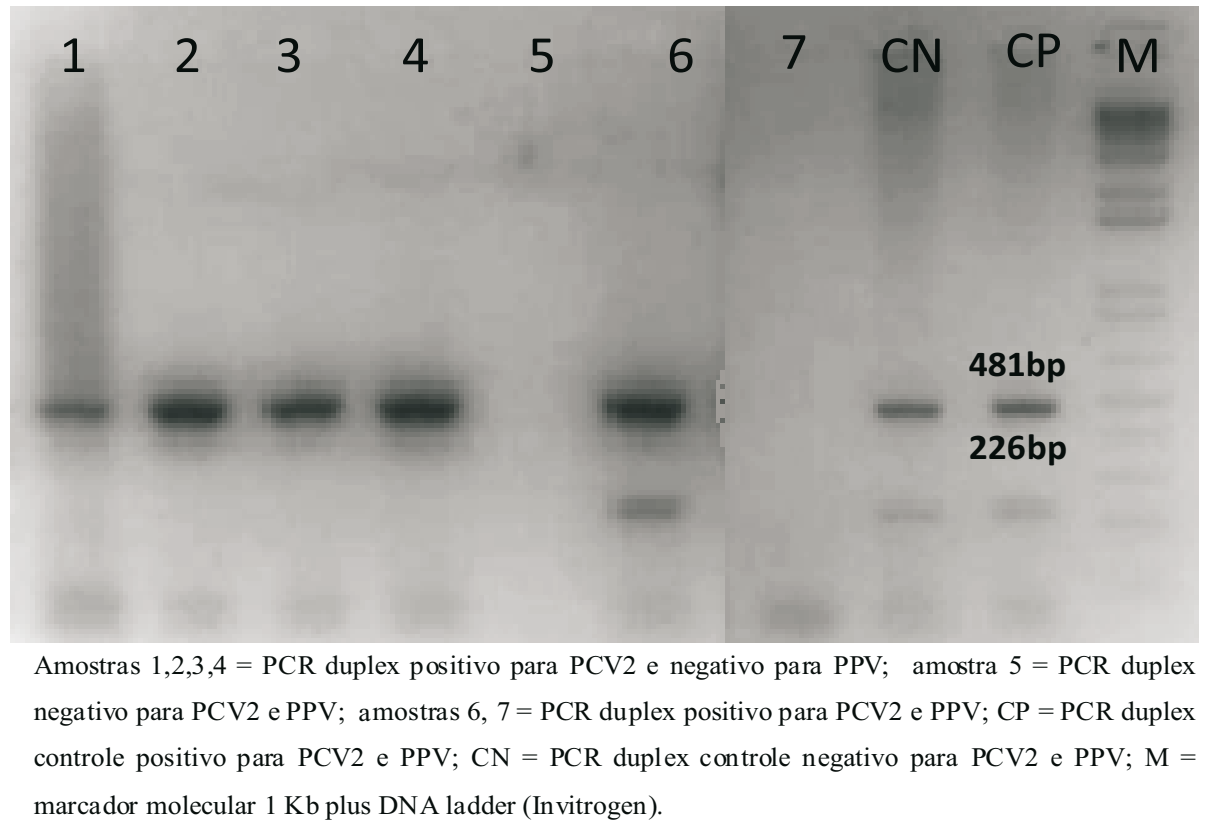

FIGURA 1. Eletroforese em gel de agarose de produtos da reação em cadeia da polimerase (PCR duplex) para circovírus suíno tipo 2 (PCV2) e parvovírus suíno (PPV) de fragmentos de coração e pulmão de fetos suínos natimortos e mumificados.

A frequência de detecção do PCV2 em fetos natimortos, mumificados e abortados nos estudos realizados no Brasil e no exterior variou consideravelmente. Os resultados do presente estudo são semelhantes aos encontrados por ZIZLAVSKY et al. (2008). Neste estudo realizado na República Checa, o PCV2 foi considerado o principal agente infeccioso detectado em fetos suínos entre os anos de 2005 e 2007, com frequência de detecção variando de $21,7 \%$ a $54,1 \%$. KIM et al. (2004), em estudo realizado na Coréia do Sul, relataram frequência do PCV2 em $13,1 \%$ dos 350 fetos mumificados, natimortos e provenientes de aborto. Entretanto, outros estudos obtiveram menor frequência de detecção do PCV2 em amostras de fetos suínos (MALDONADO et al., 2005; PESCADOR et al., 2007). No Brasil, PESCADOR et al. (2007) relataram apenas $5,7 \%$ das amostras positivas ao PCV2 do total de 121 fetos investigados. MALDONADO et al. (2005) relataram que, provavelmente, o PCV2 não seja um patógeno importante relacionado a abortos, mesmo na Espanha, onde a síndrome da refugagem multissistêmica é amplamente disseminada.

Alguns fatores podem influenciar os resultados dos estudos de frequência do PCV2 em fetos natimortos, mumificados e abortados. Entre estes, podem-se citar: a técnica utilizada para detecção dos agentes (KIM et al., 2004; PARK et al., 2005; HANSEN et al., 2010); a seleção dos fetos para o diagnóstico (PARK et al., 2005); o órgão fetal selecionado para detecção do agente viral (SANCHEZ et al., 2003; KIM et al., 2004; 
PARK et al., 2005); a idade gestacional (SANCHEZ et al., 2001); a fase clínica da doença (HANSEN et al., 2010) e a utilização de programas de vacinação para PCV2.

A detecção simultânea do PPV e do PCV2, utilizada no presente estudo por meio da prova de PCR duplex, é uma importante ferramenta de diagnóstico, uma vez que o PPV é o agente infeccioso mais relacionado a falhas reprodutivas em suínos associado ao crescente envolvimento do PCV2 nestes casos. Segundo KIM et al. (2003), os primers utilizados foram específicos, sendo que os primers para PPV não influenciaram a reação para PCV2 e vice-versa.

No presente estudo, foi utilizado fragmento de coração e pulmão de fetos natimortos e mumificados de diferentes tamanhos. A concentração do PCV2 e do PPV nos tecidos fetais varia de acordo com a idade gestacional, bem como entre órgãos de um mesmo feto, sendo o coração e o pulmão os órgãos fetais de maior concentração para o PCV2 e o PPV, respectivamente (SANCHEZ et al., 2001; SANCHEZ et al., 2003; MENGELING et al., 2006). Vale ressaltar que PARK et al. (2005) demonstraram que o PCV2 pode causar aborto, entretanto, é possível que alguns fetos não apresentem lesões histopatológicas bem como não se detecte a presença do DNA do PCV2.

Os resultados de detecção do PCV2 neste estudo demonstraram que a transmissão vertical pode ser uma importante via de infecção. Estudos monstraram que fetos expostos ao PCV2 durante a gestação podem nascer vivos, carrear o vírus e apresentar a manifestação clínica da síndrome da refugagem multissistêmica (SANCHEZ et al., 2004; ROSE et al., 2007). O PCV2 pode ser veiculado por sêmen e oócitos de reprodutores soropositivos e sem sinais clínicos da síndrome da refugagem multissistêmica (LAROCHELLE et al., 2000; BIELANSKI et al., 2004; SCHMOLL et al., 2008). GAVA et al. (2008) relataram que o PCV2 pode ser transmitido via sêmen aos fetos durante a gestação. ROSE et al. (2007) demonstraram que a vacinação de matrizes para o PPV reduz de forma significativa o número de fetos mumificados em matrizes infectadas de forma experimental com o PCV2.

A detecção do PCV2 e do PPV nos fetos natimortos e mumificados observada no presente estudo pode indicar que estes vírus sejam os causadores da morte fetal. As falhas reprodutivas associadas ao PCV2 e ao PPV foram reproduzidas de forma experimental, demonstrando a susceptibilidade dos embriões e fetos à infecção, a disseminação intrauterina e a transmissão vertical, com a possibilidade de haver interrupção da gestação (SANCHEZ et al., 2001; SANCHEZ et al., 2003; MATEUSEN et al., 2004; PENSAERT et al., 2004; PARK et al., 2005; MENGELING, 2006; MATEUSEN et al., 2007; ROSE et al., 2007; PITTMAN et al., 2008). Autores demonstraram que a coinfecção de fetos com o PCV2 e o PPV pode agravar as lesões observadas (PESCADOR et al., 2007). As lesões histológicas, tais como miocardite necrosante ou fibrosante, tem como causa tanto o PCV2 quanto o PPV. Dessa forma, apenas a histopatologia não permite o diagnóstico diferencial (HANSEN et al., 2010). Para o diagnóstico de falhas reprodutivas associadas ao PCV2 e ao PPV, autores sugerem correlacionar o quadro clínico, como o aumento nas taxas de fetos natimortos, mumificados e provenientes de aborto associados às lesões histopatológicas compatíveis e detecção in situ do PCV2 ou PPV (PARK et al., 2005; MENGELING, 2006; SEGALÉS et al., 2006; HANSEN et al., 2010).

A baixa frequência de detecção do PPV no presente estudo está de acordo com resultados apresentados por outros autores (MALDONADO et al., 2005; PESCADOR et al., 2007). PESCADOR et al. (2007) relataram $2,4 \%$ de fetos natimortos e mumificados positivos para o PPV em 121 fetos provenientes de nove granjas no sul do Brasil. Por sua vez, MALDONADO et al. (2005) não detectaram a presença do PPV em 293 fetos natimortos e provenientes de aborto na Espanha. Apesar de o PPV ser ubíquo na população de suínos no mundo (MENGELING, 2006), autores sugerem que a ampla utilização de vacina para controle da infecção pelo PPV, em vários países do mundo, seja uma importante ferramenta no controle dos problemas reprodutivos causados por este agente (MALDONADO et al., 2005; MENGELING, 2006). Há relatos de que tais vacinas foram efetivas quando testadas em condições de campo e em infecções experimentais (MENGELING, 2006). Todos os fetos avaliados no presente estudo foram provenientes de granjas com programa de vacinação para o PPV.

Os resultados observados no presente trabalho e nos demais estudos de associação do PCV2 a falhas reprodutivas fornecem subsídios para que o PCV2 seja investigado na lista de diagnóstico diferencial de 
granjas com histórico de falhas reprodutivas. Ademais, a baixa frequência de detecção do PPV e a ampla utilização de vacinas para prevenção da infecção pelo PPV em granjas de suínos no Brasil não excluem esse agente da lista de diagnóstico diferencial, uma vez que ele é considerado endêmico na população de suínos e há décadas tem sido relacionado entre os agentes infecciosos mais importantes relacionados a falhas reprodutivas.

\section{CONCLUSÃO}

O PCV2 foi detectado em 56,5\% dos fetos natimortos e mumificados e deve ser considerado no diagnóstico diferencial de granjas com histórico de falhas reprodutivas.

\section{AGRADECIMENTOS}

À equipe do laboratório Microvet.

\section{REFERÊNCIAS}

ALMOND, G. W.; FLOWERS, W. L.; BATISTA, L.; D'ALLAIRE, S. Diseases of the Reproductive System. In: STRAW, B.; D'ALLAIRE, S.; TAYLOR, D.; ZIMMERMAN, J. (Eds.). Diseases of Swine. Ames, Iowa: Iowa State Univ Pr, 2006. p. 113-148.

ARNAULD, C.; LEGEAY, O.; LAURIAN, Y.; THIERY, R.; DENIS, M.; BLANCHARD, P.; JESTIN, A. Development of a PCR based-method coupled with a microplate colorimetric assay for the detection of porcine parvovirus and application to diagnosis in piglets tissues and human plasma. Molecular and Cellular Probes, v. 12, p. 407-416, 1998.

BIELANSKI, A.; LAROCHELLE, R.; MAGAR, R. An attempt to render oocytes and embryos free from the porcine circovirus type 2 after experimental in vitro exposure. The Canadian Journal of Veterinary Research, V. 68, P. 222-225, 2004.

BRASIL. Ministério da Agricultura, Pecuária e Abastecimento. Instrução Normativa ${ }^{\circ} 47$, de 18 de junho de 2004. Diário Oficial [da] República Federativa do Brasil. Brasília, DF, 2004, n. 119, seção 1 .

BRUNBORG, I.; JONASSEN, C.; MOLDAL, J.; BRATBERG, B.; LIUM, B.; KOENEM, F.; SCHONHEIT, J. Association of myocarditis with high viral load of porcine circovirus type 2 in several tissues in cases of fetal death and high mortality in piglets: a case study. Journal of Veterinary Diagnostic Investigation, v. 19, p. 368-375, 2007.
CIACCI-ZAENLLA, J. R.; MORES, N. Diagnostic of post-weaning multisystemic wasting syndrome (PMWS) in swine in Brazil caused by porcine circovirus type 2 (PCV2). Arquivo Brasileiro de Medicina Veterinária e Zootecnia, v. 55, p. 522-527, 2003.

DAVIS, L.; KUEL, W. M.; BATTEY, F. J. Rapid Preparation of Genomic DNA from Tissue or Cultured Cells. In: Basic methods in molecular biology. 2. ed. Norwalk: Appleton \& Lange, 1994. p. 307-309.

ELLIS, J.; KRAKOWKA, S.; LAIRMORE, M.; HAINES, D.; BRATANICH, A.; CLARK, E.; ALLAN, G.; KONOBY, C.; HASSARD, L.; MEEHAN, B.; MARTIN, K.; HARDING, J.; KENNEDY, S.; McNEILLY, F. Reproduction of lesions of postweaning multysistemic wasting syndrome in gnotobiotic piglets. Journal of Veterinary Diagnostic Investigation, v. 11, p. 3-14, 1999.

GAVA, D.; ZANELLA, E.; MORES, N.; CIACCI-ZANELLA, J. Transmission of porcine circovirus 2 by semen and viral distribution in different piglet tissues. Pesquisa Veterinária Brasileira, v. 28, n. 1, p. $70-76,2008$.

HANSEN, S. M.; HJULSAGER, C. K.; HANSEN, B. V.; HAUGEGAARD, S.; DUPONT, K.; HØGEDAL, P.; KUNSTMANN, L.; LARSEN, L. E. Selection of method is crucial for the diagnosis of porcine circovirus type 2 associated reproductive failures. Veterinary Microbiology, v. 144, p. 203-209, 2010.

HOLLER, L. D. Diagnosis of swine abortions. Swine Health and Production, v. 2, p. 29-31, 1994.

JOHNSON, C.; JOO, H.; DIREKSIN, K.; YOON, K-J.; CHOI, Y. $\mathrm{K}$. Experimental in utero inoculation on late-term swine fetuses with porcine circovirus type 2. Journal of Veterinary Diagnostic Investigation, v. 14, p. 507-512, 2002.

KAICHUANG, S.; HUANRONG, L.; XIN, G.; XINNA, G.; HONG, J.; SHIJUN, Z.; HANCHUN, Y. Changes in peripheral blood leukocyte subpopulations in piglets co infected experimentally with porcine reproductive and respiratory syndrome virus and porcine circovirus type 2. Veterinary Microbiology, v. 129, p. 367-377, 2008.

KIM, J.; HAN, D.; CHOI, C.; CHAE, C. Simultaneous detection and differentiation between porcine circovirus and porcine parvovirus in boar semen by multiplex seminested polymerase chain reaction. Journal of Veterinary Medical Science, v. 65, n. 6, p. 741-744, 2003.

KIM, J.; JUNG, K.; CHAE, C. Prevalence of porcine circovirus type 2 in aborted fetuses and stillborn piglets. Veterinary Record, v. 155, p. 489-492, 2004.

LAROCHELLE, R.; BIELANSKI, A.; MULLER, P.; MAGAR, R. PCR detection and evidence of shedding of porcine circovirus type 2 in boar semen. Journal of Clinical Microbiology, v. 38, n. 12, p. $4629-4632,2000$. 
MALDONADO, J.; SEGALÉS, J.; MARTINEZ-PUIG, D.; CALSAMIGLIA, M.; RIERA, P.; DOMINGO, M.; ARTIGAS, C. Identification of viral pathogens in aborted fetuses and stillborn piglets from cases of swine reproductive failure in Spain. Veterinary Journal, v. 169, p. 454-456, 2005.

MATEUSEN, B.; SANCHEZ, R.; VAN SOOM, A.; MEERTS, P.Ç MAES, D. G. D.; NAUWYNK, H. J. Susceptibility of pig embryos to porcine circovirus type 2 infection. Theriogenology, v. 61, p. 91-101, 2004.

MATEUSEN, B.; MAES, D.; VAN SOOM, A.; LEFEBVRE, D.; NAUWYNCK, H. J. . Effect of a porcine circovirus type 2 infection on embryos during early pregnancy. Theriogenology, v. 68, p. 896-901, 2007.

MENGELING, W. L. Porcine parvovirus. In: STRAW, B.; D'ALLAIRE, S.; TAYLOR, D.; ZIMMERMAN, J. (Eds.). Diseases of swine. Ames, Iowa: Iowa State University Press, 2006. p. 373-385.

PARK, J. S.; KIM, Y.; JUNG, K.; CHOI, C.; LIM, J-K.; KIM, S-H; CHAE, C. Birth abnormalities in pregnant sows infected intranasally with porcine circovirus 2. Journal of Comparative Pathology, v. 132, p. 130-144, 2005.

PENSAERT, M. B.; SANCHEZ, R. E.; LADEKJAER-MIKKELSEN, A. S.; ALLAN, G.; NAUWYNCK, H. J. Viremia and effect of fetal infection with porcine viruses with special reference to porcine circovirus 2 infection. Veterinary Microbiology, v. 98, p. 175-183, 2004.

PESCADOR, C.; BANDARRA, P.; CASTRO, L.; ANTONIASSI, N. A. B.; RAVAZZOLO, A. P.; SONNE, L.; CRUZ, C. E. F.; DRIEMEIER, D. Co-infection by porcine circovirus type 2 and porcine parvovirus in aborted fetuses and stillborn piglets in southern Brazil. Pesquisa Veterinária Brasileira, v. 27 n. 10, p. 425-429, 2007.

PITTMAN, S. J. Reproductive failure associated with porcine circovirus type 2 in gilts. Journal of Swine Health and Production, v. 16, n. 3, p. 144-148, 2008.

ROSE, N.; BLANCHARD, P.; CARIOLET, R.; GRASLAND, B.; AMENNA, N.; OGER, A.; DURAND, B.; BALASCH, M.; JESTIN, A.; MADEC, F. Vaccination of porcine circovirus type 2 (PCV2) infected sows against porcine parvovirus (PPV) and erysipelas: effect on post-weaning multisystemic wasting syndrome (PMWS) and on PCV2 genome load in the offspring. Journal of Comparative Pathology, v. 136, p. 133-144, 2007.
ROSELL, C.; SEGALÉS, J.; FOLCH, J. M.; RAMOS-VARA, J. A.; RODRIGUEZ-ARRIOJA, G. M.; DOMINGO, M.; DURAN, C. O.; BALASCH, M.; PLANA-DURAN, J. Identification of porcine circovirus in tissues of pigs with porcine dermatitis and nefropathy syndrome. Veterinary Record, v. 146, p. 40-43, 2000.

SANCHEZ, R. E.; MEERTS, P.; NAUWYNCK, H. J.; ELLIS, J. A.; PENSAERT, M. B. Characteristics of porcine circovirus 2 replication in lymphoid organs of pigs inoculated in late gestation or postnatally and possible relation to clinical and pathological outcome of infection. Journal of Veterinary Diagnostic Investigation, v. 16, p. 175-185, 2004.

SANCHEZ, R. E.; MEERTS, P.; NAUWYNCK, H. J.; PENSAERT, M. B. Change of porcine circovirus 2 target cells in pigs during development from fetal to early postnatal life. Veterinary Microbiology, v. 95, p. 15-25, 2003.

SANCHEZ, R. E.; NAUWYNCK, H.; MCNEILLY, F.; ALLAN, G.; PENSAERT, M. B. Porcine circovirus 2 infection in swine fetuses inoculated at different stages of gestation. Veterinary Microbiology, v. 83, p. 169-176, 2001.

SCHMOLL, F.; LANG, C.; STEINGIGL, A. S.; SCHULZE, K.; KAUFFOLD, J. Prevalence on PCV2 in Austrian and German boars and semen used for artificial insemination. Theriogenology, v. 69, p. 814-821, 2008.

SEGALÉS, J.; ALLAN, G. M.; DOMINGO, M. Porcine circovirus diseases. Animal Health Research Reviews, v. 6, p. 119-142, 2005.

SEGALÉS, J.; ALLAN, G. M.; DOMINGO, M . Porcine circovirus diseases. In: STRAW, B.; D'ALLAIRE, S.; TAYLOR, D.; ZIMMERMAN, J. (Eds.). Diseases of swine. Ames, Iowa: Iowa State University Press, 2006. p. 299-307.

WEST, K. H.; BYSTROM, J. M.; WOJNAROWICZ, C.; SHANTZ, N.; JACOBSON, M.; ALLAN, G.; HAINES, D. M.; CLARK, E.; KRAKOWKA, S.; McNEILLY, F.; KONOBY, C.; MARTIN, K.; ELLIS, J. Myocarditis and abortion associated with intrauterine infection of sows with porcine circovirus 2. Journal of Veterinary Diagnostic Investigation, v. 11, p. 530-532, 1999.

ZIZLAVSKY, M.; CZANDERLOVA, L.; GAMPOVA, M.; KELLNEROVA, D.; TYDLITAT, D.; DRABEK, J. Significant role of PCV2 in reproductive disorders of sows. In: INTERNATIONAL PIG VETERINARY SOCIETY CONGRESS, 20., 2008, Durban, África do Sul. Anais... Durban: IPVS, 2008. 